\title{
Systems Issues in E-Commerce
}

\author{
Akhilesh Chandra, (Email: akliesh@ hotmail.com), University of Akron
}

\begin{abstract}
This paper profiles critical systems issues in deriving value from e-commerce initiatives. With the help of several organizational processes and functions, opportunities for accounting are identified to reduce the impending failure rate as companies experiment and adapt to the new business model. Organizations should adopt a holistic approach to address systems design, implementation and control issues. The planning and execution of e-commerce activity should focus on glitch free front-end portals that are followed up with tight back-end data integrity across various nodes of the value chain.
\end{abstract}

\section{Introduction}

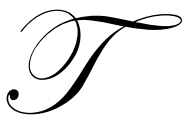

his paper describes a framework of possible value to be added by accounting systems specialists as their organizations gradually evolve towards the e-commerce based business model. Accountants should be at the forefront of technology to provide value based decision support to managers as they test and embrace this technology driven concept. As the profession responds to take a strategic role, it should preserve (and enhance) its best existing tools, and invent the rest. Gartner Group forecasts 2006-2008 as the phase-out years for e-commerce (Rozwell 2001). In such a fast moving world with shortened life cycle, the challenge is to invent and reap returns within a narrow window without the luxury of mistakes. Considering the grim prognosis of over $75 \%$ failure rate across various e-commerce projects due to failed business models, strategies and implementations in the next two-to-three years (Blodget 2000), it is the responsibility of the accounting function to provide the needed direction and decision support to help organizations steer through turbulent waters. This is possible by reinventing the tools and techniques; existing practices alone may not suffice in the new business model.

An ITC Internet Executive E-Panel study reported that over $60 \%$ of e-commerce initiatives are directed by IT executives or CEOs, $20 \%$ by marketing executives and only $3 \%$ by CFOs. These figures are perplexing, but they also present vast opportunity for the profession to seize, add value, and possibly help reverse the grim prognosis of failures. Equipped with their training and preparation in making a business case for technology drivers, accounting professionals should provide leadership in e-commerce strategies. The key issue is not just technology but the cost effectiveness, design and implementation of technology.

\section{Strategic Gap}

Now that initial indicators are a relief for an anticipated prolonged resolution of Y2K issues, most of the resources (organizational, human, financial etc.) thus freed up would hopefully be devoted to mission critical applications, such as e-commerce development. The past holiday sales over the Internet are estimated to average \$6 billion and the traditional brick-and-mortar sales to about $\$ 185$ billion. With a four-fold growth in E-Commerce business over the past year (both in terms of number of e-buyers and sales revenue) and a projected $\$ 1.3$ trillion by the end of 2003, Internet based business is increasingly being acknowledged as a growing threat to the contemporary business model. The Web is considered to have a presence of an estimated 2 million e-retailers of various scales. Refinements in technology, especially with security issues, and gradual experimentation by consumers leading to rising consumer confidence are responsible for the eventual spurt in E-Commerce related transactions. Surveys from different sources report a positive and a gradually satisfying experience by businesses (and consumers). Over $90 \%$ of the sophisticated buyers surveyed by Software and Internet Industry Association did not report any trouble transacting over the Web.

Readers with comments or questions are encouraged to contact the author via e-mail. 
Businesses are reaping benefits through aggressive and targeted marketing efforts assisted by various data mining tools.

Retrospectively, these facts pale against the expected boom in E-Commerce during 1996 itself. Further, not every E-commerce experience has been a milestone. According to a Wall Street Journal report, only the top $10 \%$ of the e-tailers have $90 \%$ of the e-business suggesting that most companies are still struggling to define the right business strategy in this new and fast emerging business model. Many e-tailers have not yet reached the breakeven point, and are operating in the expectation of making profits. According to an International Data Corporation (IDC) study, at least $10 \%$ of e-tailers substantially under-realized their expected sales - this points toward the fact that a correction is imminent in the current e-commerce frenzy market. While statistics are impressive, e-commerce, especially the b2b e-commerce is still slow to evolve. The slow development of integrated supply chains between stakeholders takes time, management vision, operational implementation at the lower level and financial resources. Negative experiences with e-commerce may be attributed in the main part, to its market driven concept without regard to business fundamentals.

\section{The Concept}

The success in e-commerce is a function of efficiency and effectiveness with which on-line companies provide choice, delivery, and full service coupled with security. E-commerce is evolving in response to consumers' preference for convenience without loyalty but with wider choices, managements' desire to reach newer and wider markets efficiently and effectively, and stakeholders' (in the value chain) insistence to access their data/information system through new/innovative ways. Figure 1 depicts the basic architecture of a typical e-commerce operation.

\section{Figure 1: Basic E-Commerce Architecture}

\section{Business to Business \\ Business to Consumer}

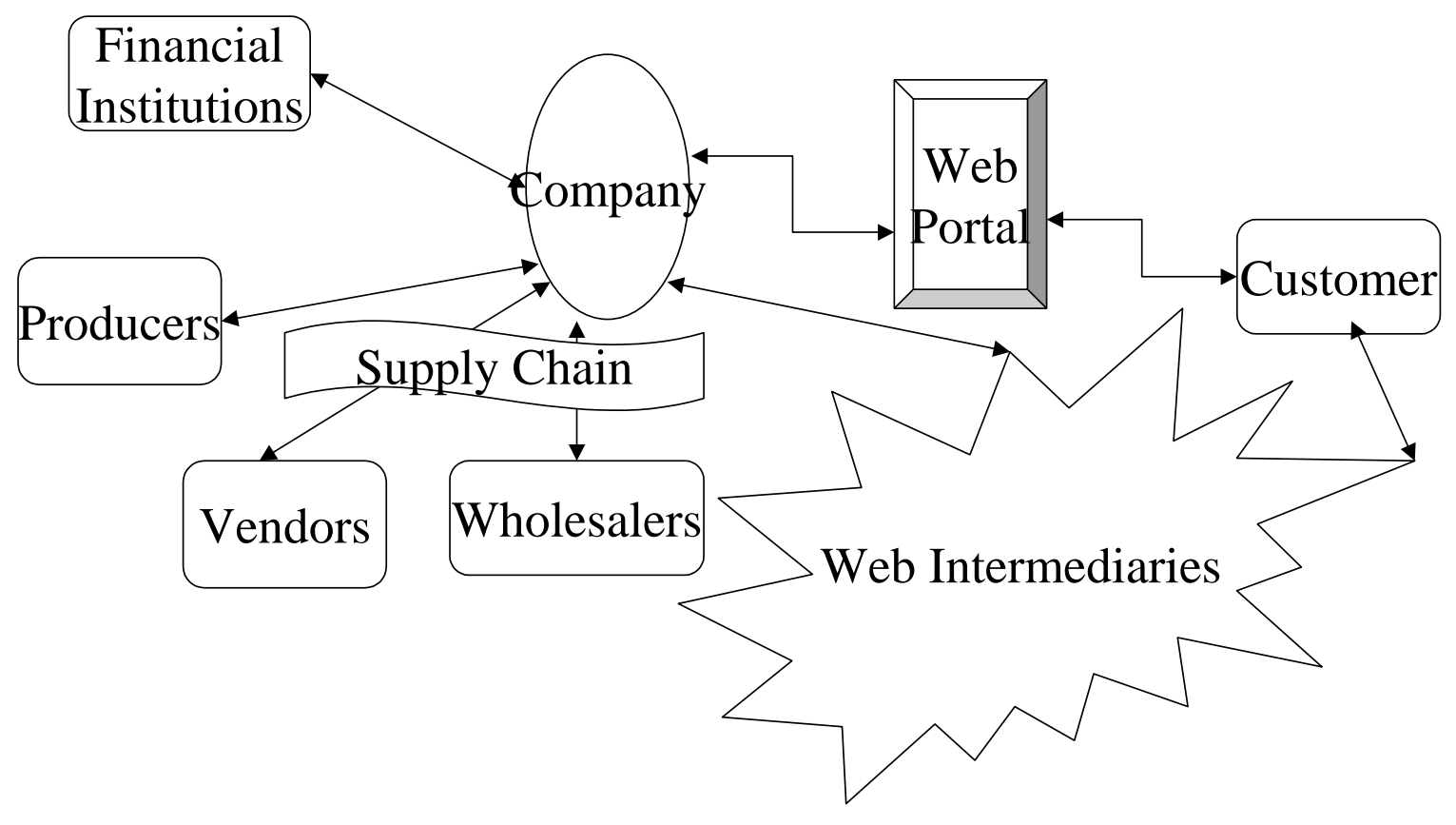


Implementation of an e-commerce business solution involves numerous challenges on way to reaping benefits. From a marketing perspective, a virtual business operation should implement targeted procedures to convert a web-surfer to a web-buyer. From a systems perspective, e-commerce solutions should be tightly coupled and integrated with existing systems (including the integration of back-office with front-end to support mission critical applications). From a management perspective, it calls for measuring effects on existing business practices and exposing inefficient procedures. From a technical perspective, it requires selection of appropriate technologies to address and control, security and privacy issues in tune with organizational goals and missions. The dynamic trading feature and potential for perfect information enabled by artificial intelligence/artificial life is forcing companies to invent value products through innovative product differentiations. As e-commerce experiment evolves to maturity, it will pose growing challenges to create and innovate strategies to affect bottom line. Policies that optimize cost and strengthen supply chain will lead the management initiatives in future stages of e-commerce development.

Of the two broad kinds of Internet oriented companies, pure e-tailers are likely to be more efficient than those that have both off-line and on-line operations due to the absence in the former of system constraints, add-on components and integration issues. In the $\mathrm{b} 2 \mathrm{~b}$ marketplace, the delayed and often missed start by most US based brick-and-mortar companies has created a learning case model for non US companies to help propel a more successful (and error-free) E-commerce growth dominated by global players, according to a Gartner Group report (Calvert and Chetham. 2000; Coulter et al. 2001). Similarly, b2c market place is fast getting globalized due in part to free Internet service (at least for now!), wiser (from the US led experience) overseas companies, and personal consumer experience generating a ripple effect.

Comparatively, the emergence of e-market makers or e-intermediaries and infomediaries, which are responsible for effecting new efficiencies and new ways of transacting business over the Web, is transforming the b2b landscape. An e-market maker enters the supply chain in vertical industries and horizontal business functions to develop a b2b IP network-based market within in an industry, geographic region or affinity group. Four broad categories of e-market makers are content and community portals, channel enablers, efficient market networks and dynamic market place. An infomediary manages user information and uses it as a bargaining chip to negotiate a price between buyers and sellers.

\section{The Usual Recipe!}

Most common response to an anticipated increase in E-commerce activity is to address the technological aspect of Internet business. Companies have been quick to add new servers or increase bandwidths. A KPMG study found prevalence of un-coordinated and un-integrated strategy across all E-commerce initiatives. Revenue driven tactical focus of E-commerce is potentially dangerous if not synchronized with internal operations and costreduction strategies. As an illustration, according to initial reports, one of the main poor performers of this past holiday season was ToysRUs; this is despite the fact that the company quadrupled its servers for the expected spike in customer traffic. Thus, a technology driven strategy neglects consideration of fundamental business drivers that may be causing bottlenecks.

Accounting function can help in the critical planning stage by analyzing and isolating significant trends in Internet traffic, effect (and causes) of sudden spikes, and forecasting process constraints. A systematic approach to address causes (as opposed to mere technological treatment of symptoms) will also help integrate E-commerce apps with business processes to create an efficient transaction processing system. In its role as a strategic partner in decision making for E-commerce initiatives, accountants would need to develop new matrices and performance measures. Most accounting systems tools and techniques were developed before the emergence of E-commerce business models, and would need modification, replacement or even invention of new tools to avoid un-intended consequences of preventing effective execution of transaction and control. For example, in the case of ToysRUs, how is the fixed cost of additional technology optimized operationally during lean periods? Unlike variable cost of extra labor during the holiday season, fixed cost of servers cannot be fired away.

However, a lack of a strategic depth, observed in most companies, remains a bottleneck in reaping full benefit of this emerging business model. Integration of front-end orders with back-end implementation and execution 
and sound supply chain management is crucial to accelerate the progress towards maturity and moderate the learning curve. Over $75 \%$ of E-commerce activities continue in the b2b domain indicating the challenge in achieving similar Internet enabled cost reduction through strategic and tactical opportunities from process automation and standardization in the b2b domain (Harreld 2001 (a), (b)).

\section{Value Framework}

This section describes functional areas where accounting systems should provide leadership and strategic support. Figure 2 depicts various processes where members of the profession should provide leadership, control and direction in e-commerce based initiatives. Each of these areas are further discussed below:

\section{Fig 2: Value Framework for System Accountants}

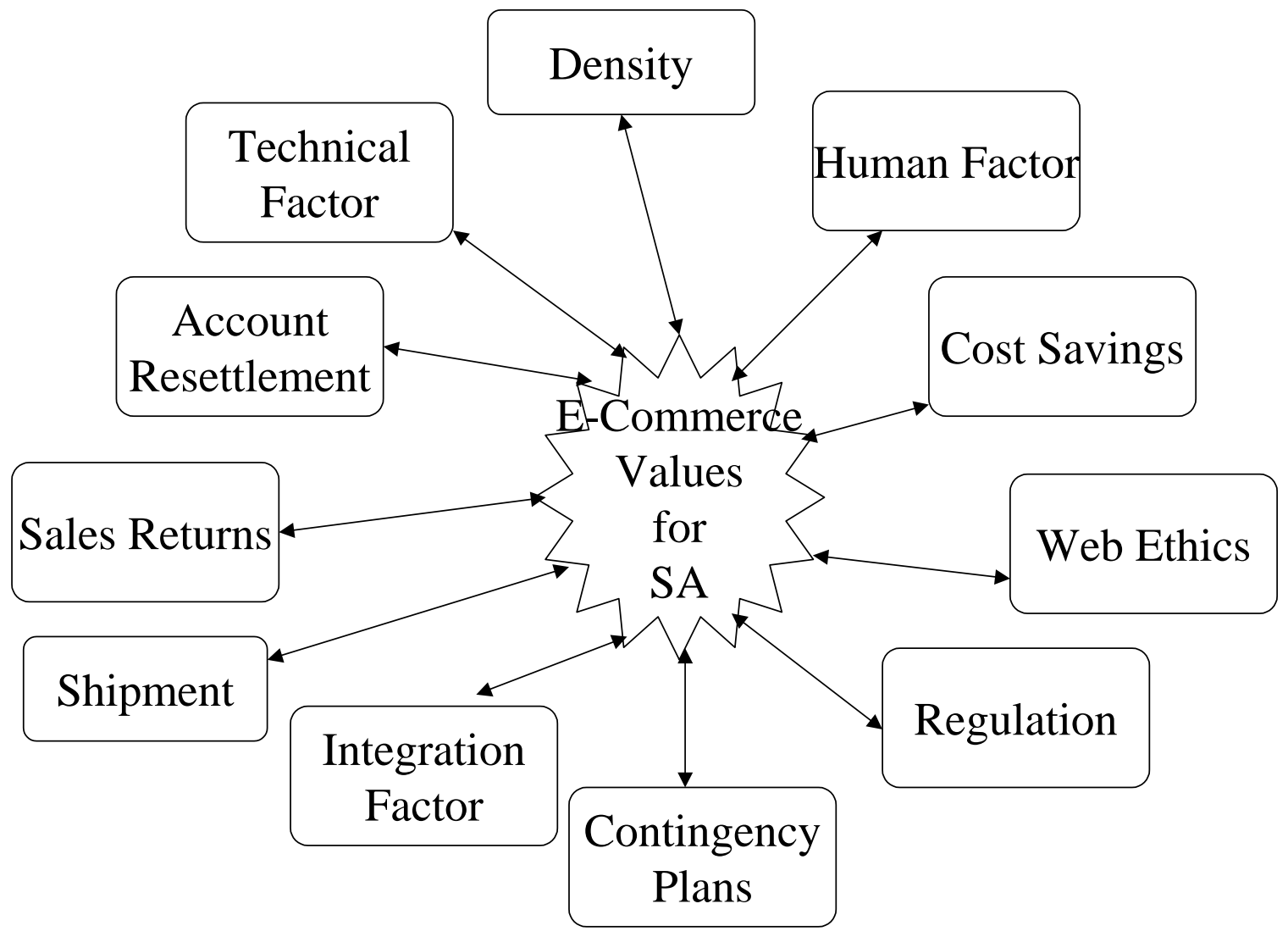

\section{Density}

There are fundamental differences in doing business between $b 2 b$ and b2c e-commerce. The goal of achieving density (or efficiency) in processing e-commerce transactions from start to finish gets complicated due to logistics. Increasing competition accompanied by thinning profit margin requires accountants to strategically isolate nonvalue-added activities and enrich value-added activities. The emerging discipline of customer relationship management (CRM) requires ascertaining and maximizing the return per customer or group of customer (Eisenfeld 2000). The opportunity to continually devise a low cost provider strategy in the face of high priced labor (due to current demand-supply situation in the skilled labor market) without compromising efficiency and effectiveness is a challenge for the management accountant. This challenge is even more paramount in a b2c transaction. The spurt in Internet grocery stores during the recent past has already caught most e-commerce firms struggling to attain their break-even-point and maintain growth. 
The efficiency argument will be even more pronounced once the current 3-year moratorium on Internet tax is lifted, partially leveling the landscape for main street retailers with e-tailers. The Congress appointed Advisory Commission on E-Commerce has a challenging task of proposing its recommendations amidst continued sharp differences that persist between the proponents and opponents of Internet tax. While existing accounting tools provide assistance in discriminating between alternative strategies, the new way of doing business over the Internet needs invention of new tools and techniques to measure and monitor quantitative and qualitative performance.

\section{Human Factor}

Despite the apparent technology driven nature of E-commerce the eventual responsibility of ensuring the execution of transactions from start to finish rests with people. Human factors will continue to be the deciding element between success and failure.

The challenge for businesses is to synchronize the front-end operations with back-end implementation. The company has to make sure that the orders are executed in a timely and cost effective manner. Thus, the human factor remains critical even though the interface at the initial stage of the transaction is virtualized. The studies by Arthur Anderson and Bizrate.com revealed that the delivery performance by brick-and-mortar retailers on-line continues to be below $20 \%$ in contrast to $80 \%$ for pure e-tailers indicating incompatibilities and difficulties in linking/extending the existing operations with online operations.

\section{Technical Factor}

The consequence of a poorly executed site (especially due to technical aspects) in today's state of development seems to have a devastating and immediate impact on sales. According to Jupiter Communications, an Internet Research firm, consumer loyalty (largely for shut-out clickers) during a sit outage instantly shifts (sometimes permanently) to another site that is more efficiently executed. About $\$ 4.35$ billion a year in E-commerce sales is lost due to technical failure, according to Zona Research. When put in perspective with $\$ 6$ billion of total estimated online sales, even the technical factor itself leaves much to be desired in a technology driven business model.

\section{Account Resettlement}

One of the hurdles, especially in $b 2 b$ growth is the delay in settling accounts over the Internet. Processing payables and receivables is still a paper-intensive labor centric process. When other components in the supply chain (such as product development, order entry, order tracking etc.) are executed in real time, the accounting part of the chain creates a bottleneck in realizing the full potential of any e-commerce initiative (Wilson 1999). A University of Tennessee study documented that over $60 \%$ receivables take more than 50 days to process. The cautious (and conservative) approach of accounting is partly responsible for this non-value added activity in the value chain. The solution is partly technical and largely the re-design of process flow. The profession needs to invent procedures that provide the traditional level of security (expected by accounting to avoid cutting a check for a wrong or un-delivered order) commensurate with modern level of convenience on a real time basis.

Most of the payments are done currently using ACH (automate clearing houses). But in the future, EBPP (electronic bill presentment and payment) services are expected to drive the electronic bill payment. In the next five years, $20 \%$ of all bill payments should be done electronically.

\section{Logistics of Sales Returns}

Management and accounting for sales returns poses special challenges in an E-commerce environment. When goods are delivered by a company other than the e-tailer (as can be normal for Internet transactions), proper and timely accounting of sales-returns (relating to inventory and accounts receivables) can be stretched in time and procedural formalities for both the firm and the consumer. This is especially true for b2c transactions. While sales over the Internet are to a large extent computerized, sales returns still remain a labor-intensive process due to yet unresolved logistics. Offline retailers as opposed to online retailers continue to be process efficient in instant consum- 
er satisfaction service. IIDC reports that with more knowledgeable consumer, customer support and on-time delivery rank as the two most critical measures of customer retention.

The dynamics of making E-commerce sales is radically different form that of sales returns. Processing a sales order virtually becomes a labor free transaction, whereas processing a sales returns is highly labor intensive. Further, the timing of sales returns accounting is a function of the terms of sales. Parties, other than the company that processed the sales order, may enforce the return policy especially where more than one node in the value chain is involved to execute a sales transaction. Performance would need to be measured by an appropriate modification of matrices that reflect the disjointed nature of sales and sales returns, and purchase and purchase returns. Comparatively, traditional retailers have a logistic advantage over their e-tailers counterparts to process returns efficiently and effectively (at least in the current state of development).

\section{Shipment}

The divergent dynamics between home and commercial deliveries in view of inherent complexities of the former provide challenging economics to invent profits in an already crowded and competitive market place with wafer thin profit margins. The low efficiency in b2c transactions is accompanied with a cautious and slow entry in it by traditional shippers. For instance, over $80 \%$ of UPS's profits are still generated by b2b transactions over the Internet.

As residential delivery from e-commerce shippers is projected to explode from the present 600,000 a day to over 4.2 million a day in 2003 (as opposed to 2.3 million per day via traditional shippers, according to a Forrester Research Report, 2000), it becomes imperative to constantly identify and enrich the value added activities for ecommerce shippers so as to sustain the low cost service advantage. The dampening effect of low per unit margin due to tough competition is traded off against larger volume to create an efficient and profitable overall e-shipment. For integrated e-commerce companies such strategies would also help transform their delivery segments from a cost-center to a profit-center. A proactive cost-accounting based response would reduce apprehensions of some analysts that b2c delivery would ever be profitable.

\section{Integration Factor}

Integration is needed at two major nodes in an e-commerce transaction. In the first stage, customers' sales orders need to be integrated with its follow-up at the corporate office. In the second stage, the company's systems should be seamlessly synchronized in real time with its suppliers, manufacturers, and other stakeholders in the value chain so that they can implement the order from their locations itself. The later integration will reduce the need to handle and manage inventory by the e-tailer, thereby, improving the order process time and response time. The accounting systems can help in this respect by identifying relative performance at each node along the chain from start to finish. Enhancing the strength and capacity of the weakness link will help the organization improve the returns on e-commerce initiatives.

Further, an assessment of tolerance limit of the system and development of contingency plans are needed to determine the investment required for increasing throughput during uncertainties. A direct and only response by increasing server and bandwidth capacity alone without regard to business fundamentals can be self-defeating as experienced by ToysRUs this past Christmas season. The company increased technical capacity by quadrupling its server/bandwidth and still could not deliver goods on time.

The need is to adopt a holistic approach to the problem instead of treating symptoms in isolation. According to Yankee Group's analysis (2001), in most cases the bottleneck is not the limited technical capacity of server/bandwidth but in business fundamentals. The contemporary data mining tools (e.g., RFM, logistic and non linear regression, decision trees, CHAID and CART, neural networks etc.) will assist the accountant to understand and analyze patterns in spike and troughs in various variables in a cause-effect framework. An analytical study would then help to more precisely and systematically respond to unforeseen contingencies by integrating current systems with e-commerce applications. A scientific data mining effort should include a focused definition of business prob- 
lems, performing a data audit (to ensure data quality) and exploratory data analysis, selecting the modeling tool suited to the problem's characteristics and data availability, evaluation and validation of the model, and re-building of the model to optimize results.

Integrating current accounting tools with data mining techniques will help maximize ROI for e-commerce projects, conduct customer segmentation and profiling necessary to perform mass customization and CRM so that most profitable customers and prospects are identified, retained and developed. This so called "relationship marketing," if left for the marketing department alone, can ignore significant cause-effect relationships leading to potential competitive disadvantages.

Further, data mining would also add value through satisfying customers' information requirements in the emerging one-to-one customer paradigm, and the customer becoming more knowledgeable and demanding as reported by IDC.

\section{Contingency Plans}

The rapid pace of change over the Internet requires a constant level of preparedness to deal with uncertainties for a quick response time. The accounting function should help companies prepare contingency plans to address costing, administrative and logistic issues during uncertainties such as site outage. Flexible budgeting technique for alternative scenarios will be useful to managerial decisions to gain competitive advantages. As management proactively plans to prepare for spurts in E-commerce activity, especially during holiday season, the responsibility of the accountant lies in evaluating alternatives on the basis of investment in infrastructure including bandwidth/server capacity, seamless integration of technology with existing assets, synchronization of front-end and back-end performance, tightening loose ends in supply chain management and CRM. The new business model also calls for the development of e-commerce based tools indices that capture and monitor levels of activity over the web. This may require either a modification of existing or generation of new tools. As part of the monitoring team charged with streamlining the throughput, the systems accountant will be responsible for identifying the needs of and bottlenecks in the potential system, and the capacity limits of the existing system. For example, the most common disparity between order placement and order fulfillment occurs because of non-coordinated or disintegrated value chain.

\section{Regulation}

Regulation of e-commerce activity continues to be a thorny issue between its proponents and opponents. Both Global Business Dialogue on E-Commerce (GBDe) and the World Intellectual Property Organization (WIPO) oppose the anticipated role of regulatory authorities in the Internet enabled world economy. The opposition stems from possible incompatible/conflicting (country to country) regulations that may stifle the free flow of Internet transactions. In sharp contrast to this is the position taken by the consumer group that wants strict international guidelines and control by the State, according to Consumer Policy Committee of the OECD (Dryden 1999, Putnam et al. 1999). Jupiter Communications found a high level of mistrust by consumers (to the extent of $64 \%$ of respondents) with their private data regardless of the claims made by on-line merchants in their privacy policy disclosures. But businesses favor self-regulation to promote responsible industry data protection practices and other E-commerce issues.

In this respect, accounting has a vital role to play to appropriately develop and design internal controls, and invent new auditing techniques to monitor the E-commerce activity of the organization. Leaving this task to the IT department alone can seriously undermine the business and accounting related issues that need to be considered in such a mission critical self-regulation. As part of the task force charged with proper governance of activity over the Internet, the accounting function has to proactively prepare itself for a future where a typical e-transaction could be under the radar screen of multiple countries and local governments due to evaporation of cross national borders. On-line security (and legal) issues could have a pronounced impact on the design and implementation of control systems. 
With regard to privacy issues, the accounting function can help alleviate concerns by promoting continual communication with consumers, education of buyers, refinement and development of industry standards (through new and innovative approaches). Professional accounting bodies should take a leadership role in this respect by putting into action a task force to develop new accounting services that address issues through professional pronouncements. Such an organized approach would foster added consumer confidence in e-commerce related transactions. For example, formation of an independent group within the organization headed by an accountant to oversee the planning, implementation and reporting of e-commerce controls would provide objectivity and reliability to selfregulatory efforts. The members of such a group may be drawn from different divisions including IT/IS. The group should be given an autonomous authority and responsibility reporting to the board. The goal is to impart a sense of transparency in the group's objectivity and independence with which it discharges its responsibilities.

\section{Web Ethics}

Adherence to a code of conduct and ensuring ethical/moral behavior of company personnel is the corner stone of the accounting profession. The National Consumer League (NCL) found incidences of un-authorized credit card charges, misrepresentation, over-billing, and non-delivery by e-commerce companies (NCL 2000). Sound and effective internal controls that are constantly monitored and evaluated would assist in maintaining an element of transparency in the eyes of the consumer and increase its confidence. In an era where consumer data is a source of revenue and also of blackmail for ransom by cyberspace fraudsters (the latest example being over 300,000 credit card numbers stolen over the Web from CDStore.com's site for a ransom uncovered on January 10, 2000), safety of financial and other personal information is one of the main issues. The issuance during 2000 of the "Guidelines for Consumer Protection in the Context of E-Commerce" by OECD is designed to protect the rights of consumer in the global marketplace (OECD 2001). The accountant can help ensure the effective implementation of these guidelines. Despite a projected 100-fold increase in E-commerce activity to $\$ 220$ billion in 2001, the FTC is concerned about equally sharp rise in fraudulent transactions over the net. In view of the potential to invent new ways to commit fraud, the accounting professional bodies such as IMA, IIA, AICPA, and ISACA should establish a central database to deal with unethical practices. Such a service would be especially useful to small E-commerce companies that are constrained by resources and unable to match the investigative capability of larger organizations.

\section{Cost Savings}

The need for adopting cost savings strategies assumes significance in view of the impending expiration of the current moratorium on Internet taxes by the Clinton administration. When (and if) this happens, the price advantage argument would require online companies to further prune their operations (Sharrard et al. 2000). The consumer's loyalty would be guided by both price efficiency and the convenience of buying over the Internet.

The cost savings claimed for e-commerce is more applicable for $b 2 b$ than for the $b 2 c$ mode. In the latter mode, service over the Internet effectively amounts to mass-customization. Companies have not yet focused on the cost-benefit analysis of such one-to-one marketing. The accounting tools and techniques can help in isolating customer centric approaches that are either profitable or revenue eating. The fast emerging concept of CRM encompasses various aspects of customer centric services where accounting has a vital role to play. CRM is not a marketing concept alone; it is all-pervasive in import with opportunities for systems accountants to add value through their expertise and experience. Further, widespread use of artificial (shopping) agents and movements towards consumer groups to negotiate a "group price" directly from the manufacturer would force companies to be cost effective more than ever before. Therefore, the e-commerce business model must be integrated with the overall enterprise business strategy.

\section{The Future}

Most e-commerce concerns that occupied attention in 1996 are still valid today, though the intensity of some of them is certainly diluted. Even today, there exists a low penetration ratio, absence of financial infrastructure (to support payable/receivable causing delay in executing orders), concerns about security/privacy issues, and 
uncertainty over cross-border regulations, ethical practices and their enforcements to protect stakeholder's interests. The global e-commerce (even on a b2b mode) is still cautious and experimental.

As the e-commerce experiment gradually picks up, business cases based on success and failure need to be developed. Such studies would provide groundwork for establishing standards for benchmarks on functional, divisional, unit and industry bases useful for continuous improvement. The application and enforcement of taxation and custom duties of e-commerce transactions, legality of e-contracts, e-documents, e-signatures, resolution of disputes and liability status would require refinements and precision. The nature, dynamics and impact of the E-commerce model should be investigated at both inter-organizational levels (i.e., b2b and b2c) and intra-organizational levels (i.e., workflow, ERP systems, integration with intranets, VPNs and external systems such as online shopping malls). The need is to create a database of best practices that can be benchmarked for learning and innovation through models of critical success factors that aid adoption, diffusion, and assimilation of processes.

The accounting function can help by providing the leadership to companies to clearly become e-commercecentric. While the consumer-centric focus of e-commerce has enhanced the growth of CRM causing investments on front-office applications, development of back-office applications has received reduced attention. Future growth of e-commerce will necessitate seamless integration of the two to ensure a business-centric development of CRM. Performance matrices for "dot.coms" are likely to be different than for "click-and-mortar" sites (those with offline stores as well). The web site and corporate entity are usually treated as separate entities with different operating rules. Steadily rising consumer expectations is causing companies to constantly reinvent themselves to meet information requirements. Especially, in b2c mode, the customer wants and expects companies to complement ecommerce portals with live sales support.

\section{Suggestions for Future Research}

Future work can build on our framework to lend empirical validity through field research or case analysis. The best practices in each of the areas discussed in this paper would help develop the much needed theoretical basis as organizations adapt to the new business model. Finally, there is a need to extend and modify the contemporary accounting based performance matrices that accounts for the e-business realities

\section{References}

1. Blodget, H quoted in "Caught in the Net" by Judy Ward in Executive Edge: Strategic Advantage Through Technology. August/September, p. 56-59, 2000.

2. Calvert J. and A. Chetham. Asia/Pacific ISP Market Trends. Gartner Dataquest. 18 December, 2000.

3. Coulter, M. S. Dux, B. Shankar, M. Tissot, and L. Unden. Western European Public Data Services: Internet Growth Starts to Drive the Market, Gartner Dataquest. 3 January, 2001.

4. Dryden, J. Regulating Electronic Commerce, Privatization, Self-organization, and Governance, Workshop of the Institute for Prospective Technological Studies and the European Commission, June 14-15: Seville, 1999.

5. Eisenfeld, B. To Do Well, Do Right... By the Customer. Executive Edge: Strategic Advantage Through Technology, August/September, p. 21-22, 2000.

6. Harreld, H. (a). B-to-B Integration Vendors in Market Shakeout. InfoWorld, March 16, 2001.

7. _ (b). B-to-B Internet Commerce Projections are Scaled Back. InfoWorld. March 13, 2001.

8. NCL. Holiday shopping on the Internet. NCL Bulletin, Vol. 60, No. 3, 2000.

9. OECD. OECD Guidelines for Consumer Protection in the Context of Electronic Commerce. http://www.oecd.org/dsti/sti/it/consumer/prod/guidelines.htm, 2001.

10. Putnam, M., S. Dolberg, and J. Sharrard. Regulating Global eCommerce. Forrester Research, Inc., 1999.

11. Rozwell, C. Fear and Loathing: The E-Biz Trough of Disillusionment. Gartner Group Inc., Research and Advisory Services, April 3, 2001.

12. Sharrard, J, J. C. McCarthy, M. J. Tavilla. Making Net Sales Tax Pay. Forrester Research, Inc. November, 2000.

13. Wilson, D. C. Financial Advisory Services - Americas Theatre Marketing, PricewaterhouseCoopers, 
March 22: http://www.pwcglobal.com, 1999.

14. Yankee Group. Application Integration in the Brave New Internet Era. Vol. 6, No.1, January. http://www.yankeegroup.com/webfolder, 2001.

Notes 